Ethiopian Journal of Environmental Studies \& Management 7 Suppl.: 695 - 708, 2014.

ISSN:1998-0507

doi: http://dx.doi.org/10.4314/ejesm.v7i1.1S

Submitted: March 31, 2014

Accepted: October 24, 2014

\title{
APPLICATION OF GEOGRAPHIC INFORMATION SYSTEMS IN LAND SUITABILITY RATING FOR LOWLAND RICE PRODUCTION IN BENUE STATE \\ ADE, M.A.
}

Department of Geography and Environmental Management, University of Abuja, P.M.B 117

Abuja, Nigeria Email: mercy_ade@yahoo.com

\begin{abstract}
The study assessed suitability of land for lowland rice production in Benue State using Geographic Information Systems (GIS). Soil map with 12 mapping categories evaluated using FAO, 1979 framework. The soils were reclassified using critical limiting factors based on nutrient, rainfall, temperature and other soil parameters. The soil mapping categories are $2 a$ upon Recent Alluvium, 15a (Aeolian sands) 15d, 17, 18a, 18d, 19a, 19c, 20b 21b, $22 b$ and 24a.The assigned soils had final rating of from 0.0 permanently unsuitable (0.2) as unsuitable (0.5) marginally suitable (0.8) as moderately suitable and (1.0) as highly suitable. The raw samples taken and those established from soil survey reports were coverted to grid. An analysis in Arcview called overlay was done and further the results was reclassed resulting to a suitability map. while distance analysis / buffering for determination of further suitability was carried out along the drainages. It was discovered that each soil mapping unit had different nutritional status, with variance in certain degrees or deficient in other important nutrients. Results show suitable lands are deficient in most soil nutrients and did not meet some important limitations. A land area of about $14234.0612644 \mathrm{~km} 2$ (44.5\%) is highly suitable, $9151.0312098 \mathrm{km2}$ (28.6\%) moderately suitable, $1372.4023436 \mathrm{km2}$ (4.2\%) as marginally suitable and $6201.2020400 \mathrm{~km} 2(19.4 \%)$ as unsuitable while drainage and built up area have an area of $900.530116 \mathrm{~km} 2(2.8 \%)$ and $138.00 \mathrm{~km} 2(0.5 \%)$ respectively.
\end{abstract}

Key Words: Land Evaluation, Overlay, Suitability, Reclass, GIS

\section{Introduction}

The productivity of the agricultural sector in a developing country such as Nigeria is of great importance not only to the rural poor but to the country as a whole (McNamara: 2003). It allows the country to be selfsustaining in food production, alleviate poverty and increase in global involvement. Geoformatics and other remote sensing applications can be important tools to quickly identify areas suitable for agricultural exploitation and expansion.

Nigeria is one of the most populous countries in the sub-Saharan Africa with a population of over 100 million people growing at a fast rate. Hence the population pressure is and will lead to an increase in food demand. Also the movement of people from farming to other sectors of the economy, inadequate wetlands and erratic rainfall for rice cultivation which has strained food supply is of concern. Also the planting of wrong crop on wrong soil type can lead to under-utilization or over exploitation of the land and the cultivation of the crop under serious constraints is what this work seeks to address. 
Furthermore, due to the said ban on importation of rice and the desire to encourage local production of rice and its subsequent exportation, a number of interests have arisen in the area suitable for rice so as to estimate the production and boost production of same

From its inception, the Obasanjo administration (1999) made a firm commitment to restore Nigeria's Agriculture to its past eminent position in the economy of the world. It was realized that the contribution of the sector had significantly dropped from being a major foreign exchange earner and resource reservoir to the present status of low supply deficits in both food and industrial crops. On this basis, the government convened several stakeholders' fora on Cassava, Rice, Vegetable Oil Development Programme (VODEP) and Tree Crops. This led to the inauguration of various committees under the chairmanship of the Honourable Minister of Agriculture and Rural Development that developed the blueprint for the implementation of the "Presidential Initiatives on Cassava, Rice, VODEP and Tree Crops. The blueprint was subsequently approved by the Federal Executive Council (FEC) with the recommendation that the take-off funds be made available for project implementation. Rice production in Nigeria is dominated by small holder farmers with 0.5 - 1.5 hectare per farmer using manual labour for virtually all its operations. Presently over 52 rice varieties with yield potentials of between $2-$ 8 tonnes of paddy per hectare and maturity periods of 95 - 140 days had been developed by both National and International Research Institutions (Presidential Initiative,2003). Most of these varieties have been found to be suitable for cultivation in diverse agro ecological zones(Presidential Initiative, 2003). Current national demand for rice is estimated at 5.0 million metric tonnes of milled rice while the current production status is estimated at 3.0 metric tonnes leaving a deficit of 2.0 million metric tonnes. Consequently, the country resorted to rice importation to bridge the gap. The national rice import bill was as high as N96 billion in 2002. However, there was a slight decline in rice import bill in the year 2004(Presidential Initiative, 2003). The enormity of our national demand and the need to conserve foreign exchange show clearly that we cannot depend on the level of production by the small holder farmers. Thus, the urgent need to address the production constraints for increasing output to satisfy domestic consumption and even producing for export becomes paramount.

Rice is an important staple food or crop in Benue state, and has recently become a crop of increasing importance in Nigeria. Its importance is derived from its diversified uses as food, especially ease with which it can be of converted into traditional food dishes. The production profile of rice is influenced by widely varying agro climatic and socioeconomic factors. It is restricted to areas having warm temperatures and abundant water. It can be cultivated in virtually any region having 4 to 6 months. With mean temperature of 20 to $38{ }^{\circ} \mathrm{C}$ and an average temperature of at least 20 to $25^{\circ} \mathrm{C}$ and a minimum of $10^{\circ} \mathrm{C}$.

In warm dry areas rainfall can be replaced by irrigation. Rainfall of $1000 \mathrm{~mm}$ or more, $1400 \mathrm{~mm}$ during growing season is needed while rainfall at $800-1000 \mathrm{~mm}$ is considered as marginal. Relative humidity may affect the sensitivity to diseases, also with duration of sunshine, type of landform, wetness conditions, physical soil conditions, fertility status and salinity/salinity characteristic may have impacts on productivity.

Rice can be cultivated according to different broad land utilizations. These include; rainfed rice, bunded rice, rice 
cultivation under natural floods and irrigated rice. For the purpose of this study, rice cultivated under natural floods (lowland) rice will be the focus of this study.

Rice cultivation on natural floods is another widespread type of rice farming in many tropical countries. It is practiced in floodplains where farmers benefit from the natural floods to cultivate rice. This type of rice farming, in terms of landform, is the main cultivation pattern in meander, lacustrine and marine floodplains (McNamara, 2003).Cultivation on natural floods can be practiced on some parts of alluvial terraces where floodwater, as a result of run-off from higher landforms, accumulates during the monsoon period.

A systematic approach that combines all these factors to produce information on land suitability will be useful but to farmers and agricultural planners.

Land suitability is the fitness of a given tract of land for a defined use (FAO, 1979). Differences in the degree of suitability are determined by the relationship, between benefits and required inputs associated with the use of the tract in question. Generally two types of suitability classification are considered: actual and potential suitability classification. The actual suitability classification relates the suitability of land units for a specific use in their present conditions, without major land improvements; suitability being assessed in terms of expected benefits in relation to required recurrent and minor capital expenditure. While Potential suitability classification relates the suitability of land units for the use in question at some future date after major improvements have been effected where necessary.

Land characteristic is optimal for the considered land utilization type, the maximal rating of 100 is attributed; if same is unfavorable, a minimal rating is applied. The ratings of the different land characteristicslqualities are finally multiplied in order to obtain a land index Sys (1985).

A systematic approach to produce information on the suitability is needed. The information can be separated into layers to model suitable area as a set condition. An FAO guideline on land evaluation system (1983) is widely used. The system was based on defined land qualities as related to land use requirement. Rice is adapted to specific hydrologic conditions and therefore, specific crop requirements have to be suggested for each, particularly with regard to landform, flooding and physical soil characteristic. The crop requirements are set up as to use the FAO system (FAO, 1976) whereby land characteristics are quantified. The class is attributed to the most important limitation level. The suggested requirements are therefore a basis for a qualitative evaluation.

Geographic Information Systems (GIS) played an important role in soil survey and land evaluation for land use planning in the Lao PDR which was carried out by Inthavong Thavone.This study addressed in particular the use of Geographic Information Systems to help determine which areas in the Central Part of the Lao PDR are most suitable for rain fed lowland rice, cash crops and fruit trees. The study established suitability ratings for different types of crops in different parts of the country given different soil, physical and other factors.

Again another research on rice production practices in Mankrua valley, Ashanti region Ghana was done by Opoku-Akpan et al(200) of the Crop Research Institute in Kumasi. Based on a far survey carried out on rice farmers in the Mankrau valley near Kumasi, an analysis of the production practices, constraints and the level of use of improved technologies by rice farmers in the study area was developed. 
Thailand is one of the countries with the actual practice and such GIS works. Agricultural development in Thailand has rapidly progressed since the 1960's.One of such works is the land suitability analysis concerning water resources and soil property carried out in Japan international research centre for agricultural sciences (JIRCAS) by Yukiyo, (2003). A multi-temporal data observed by a Land Sat 5 TM, soil maps and topographic maps drawn on a 1:50,000 scales were used for analysis. In the study, land suitability for major crops was determined by soil property and water resources availability using LDD (soil survey and classification criteria) and the water analysis restricted to surface water. Digital numbers of the surface water were looked at and thresholds determined and overlaid from three different TM data to obtain a water resource map for the rainy season.

This study was an attempt to identify areas suitable for lowland rice production in Benue State using GIS techniques.

The research aim was to employ the techniques of geographic information systems in selecting suitable locations for lowland rice cultivation in Benue state.

\section{Objectives}

To achieve the aim of this study, the following objectives were specified:

- To collect and collate the basic climatic and soil requirements for rice production

- To rank and weight these parameters in order of their importance on the basis of the above

- Identify areas within Benue state suitable for rice production using GIS

\section{Study Area}

Benue state is located in the central middle belt of Nigeria in the River Benue basin and trough.The Benue valley is free from rapid falls, thus forming extensive flood plains and alluvial swamps with braided stream channels. The state is located in the lower Benue with extensive plains of less than $150 \mathrm{~m}$ above sea level. The areas are flat to nearly level and undulating with the eastern part of the state having an altitude of $1200 \mathrm{~m}$ above sea level. with major tributaries like river katsina pai, wase, mada, shemankar , and donga, Mu, Gwer ,Guma, Aloma, kwangere, konshisha, Be etc which also has extensive alluvial floodplains.

The soils in Benue are developed from the weathering of cretaceous sediments consisting of sandstones, siltstones, shales, and mudstones they show considerable variability in texture with medium textures predominantly (Soil Report, 1985). Alluvial soils are however located adjacent to the drainages of the state ranging from the ancient to recent alluvial deposits and attract intensive cultivation.

The state is characterized by tropical vegetation zones namely lowland rain forest, derived savannah woodland and open savannah woodland with gazetted forest reserve having Gmelina and teak as common species. The river banks are extensively vegetated with cover comprising farm tracts, tall grasses and forest. Landuse around the riverine area is mainly arable farming. It also has grassland and agricultural lands. The climate of the area is the tropical climate with distinct wet and dry seasons. The rainy season commences in April to October with mean annual rainfall of between 800$1500 \mathrm{~mm}$. Temperature is high all through the year but highest round April and May. Mean temperature range is between $32{ }^{\circ} \mathrm{C}$ to $33{ }^{\circ} \mathrm{C}$, while relative humidity is dependent on seasons but ranges from $50 \%$ to $80 \%$ being lowest during the dry season and highest during rainy season. 


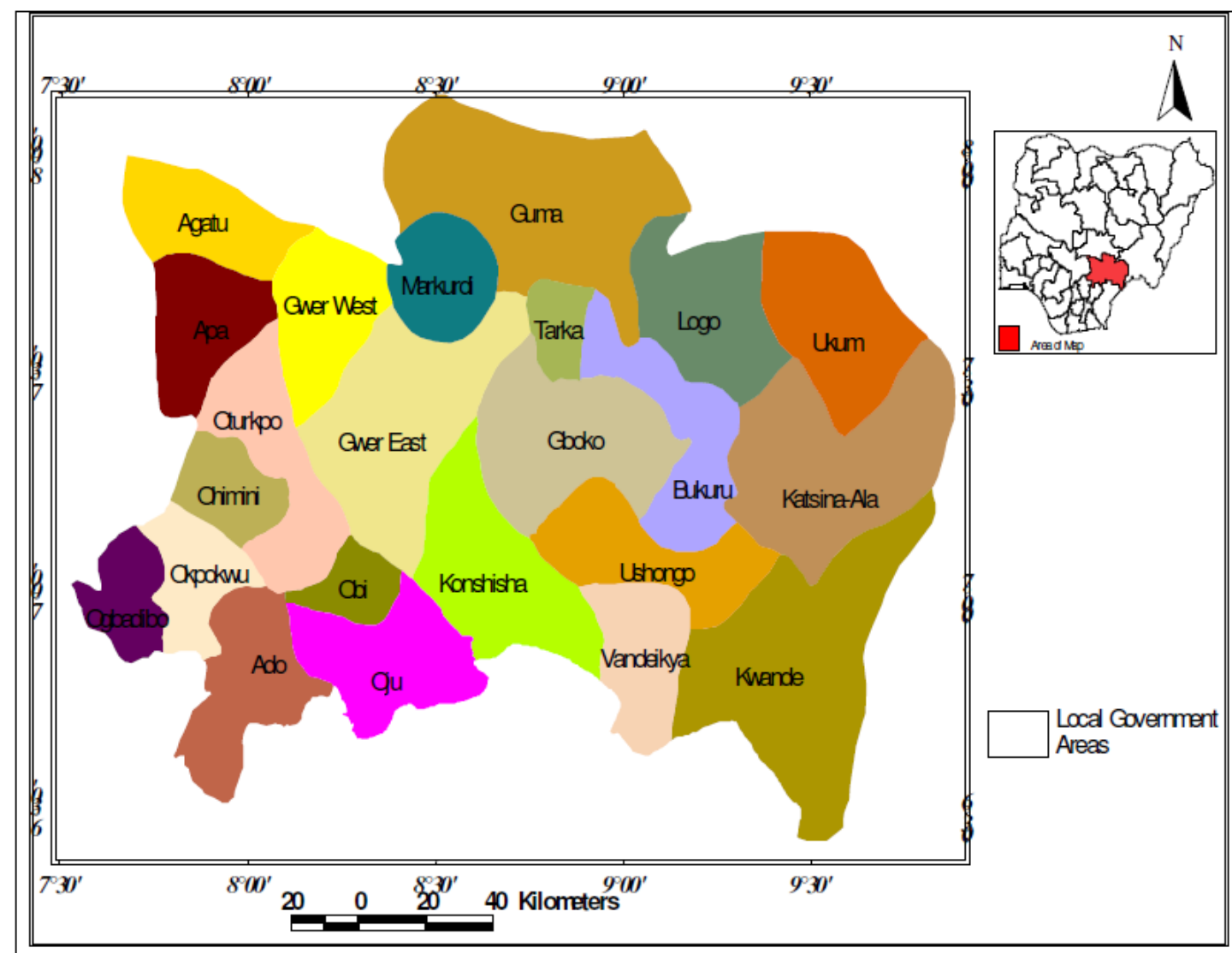

Figure 1 map of Nigeria showing study area

\section{Materials and Methods}

The most crucial of all data is the soil data through which many parameters being extracted were used to determine suitability. the soil, relief and geologic map was gotten from the soil science department, university of agriculture Makurdi while the back up documents that contained the nutrients and other parameters were obtained through a reconnaissance and semi-detailed survey of Benue state and river Benue respectively from the federal department of agricultural land resources. Other maps like land use, drainage and so on were obtained from the Final report of a feasibility studies by Sigwa Nigeria Ltd and a report of Environmental Action Plan of Benue State by FORMECO.

According to Sys (1985), in order to carry out a land evaluation and suitability rating, Land is looked at in terms of characteristic and qualities. Land characteristics are measurable properties of the physical environment directly related to landuse. This includes climate, topography, wetness, physical soil characteristics, like texture, soil depth, cation exchange capacity, organic matter, salinity and alkalinity status. This is used in combination with land qualities or one used as a replacement for the other. Land qualities are measurable, calculable or estimable attributes, representing the immediate requirements of the land utilization types. These include; water availability, oxygen nutrients availability salinity absence, nutrient and water retentions and these are rated as optimal, marginal or suitable.

Therefore evaluation of characteristics and qualities for specific land use is an essential stage in the overall evaluation work. 
Application of Geographic Information Systems in Land Suitability Rating................ADE, M.A.

This can be done using the relative limitation scale approach or the parametric approach or model. For the purpose of this work, the parametric model was used. This consists of a numeral rating of the different limitation levels of land characteristics in a normal scale from maximum (normally 100) to a minimum value. If the land characteristic is optimal for the considered land utilization type, the maximal rating of 100 is attributed; if same is unfavorable, a minimal rating is applied. The ratings of the different land characteristicslqualities are finally multiplied in order to obtain a land index.

\section{Data Types \\ - Rainfall data of Benue state. \\ - Soil map and metadata \\ - Relief and drainage map \\ - Temperature data \\ - Administrative map \\ - Land use map \\ - Vegetation map}

From the data sources mentioned earlier, the maps were scanned using an A3 scanner, converted to a Jpeg format and imputed into ArcView 3.2a environment. The maps were then registered in their actual geographic coordinates in degree decimals for spatial georeferencing. These maps were then digitized and captured with their different attributes in ArcView 3.2a as polygon data for soil, relief, administrative, maps etc while drainage, road network; rivers were digitized as line data and settlements as point's data.

In order to develop a set of themes for evaluation and ultimately to produce a suitability map for rice, the crop requirement in terms of land qualities was used from the soil survey report of the federal Department for Agriculture and Land Resources. The land qualities used in this evaluation thus include a number of land characteristics: Water Availability (W), Nutrient Availability Index (NAI), Water and Nutrient Retentions(R), Salt Hazard (S) and
Topography $(\mathrm{T})$ each land characteristics was considered as a thematic layer in the GIS. These were extracted from the maps and other data collected form the database. Determinations of the various factors and values assigned are summarized in the Table. 1

The Water Availability was based on the amount of annual rainfall and availability of irrigation. The Nutrient Availability Index was based on the method developed by Radcliff et al (1982) and is given by NAI $=\mathrm{N}$ x P x K x pH x Mg x Ca x Org M. Spatial information on each diagnostic factor of NAI (N,P,K, pH, Mg, Ca, Organic matter) were obtained from soil map. The water and Nutrient Retentions were estimated from the diagnostic of soil texture and particle size, CEC (Cations exchangeable Capacity), Base saturation and Drainage. Higher clay content results in high retention of water and available nutrients.(see figure 1 below). Soil map provided information on soil texture and particle size. The soil salinity and Acidity is an important edaphic constraint in the region. The availability of soil salinity data was used to assign factor rating (see figure 2 below).

The diagnostic factor of topography $(\mathrm{T})$ is a combination of landform and slope gradient and Drainage. The landform, slope and Drainage has predominant effect on the retentively of water during the growing period. Each of land qualities with associated attribute data were digitally encoded in a GIS database to eventually generate five thematic layers. The diagnostic factors of each thematic layer were assigned values of factor rating as identified in Table 3.2.1. The evaluation model is defined using the value of factor rating as follows: Suitability $=\mathrm{W} x$ NAI x R x S x T. These five layers were then spatially overlaid with the use of GIS software ArcView 
Table 1: Factor rating of land quality for lowland rice

\begin{tabular}{|c|c|c|c|c|c|c|c|}
\hline \multirow{2}{*}{ Land quality } & \multirow{2}{*}{ Diagnostic Factor } & \multirow{2}{*}{ Unit } & \multicolumn{5}{|c|}{ Factor rating } \\
\hline & & & 1.0 & 0.8 & 0.5 & 0.2 & 0.0 \\
\hline $\begin{array}{l}\text { Water } \\
\text { Availability (W) }\end{array}$ & Rainfall/Irrigation & m.m. & $\begin{array}{l}>1800 \\
\text { or irrigated }\end{array}$ & $\begin{array}{l}1200- \\
1800\end{array}$ & $1200-900$ & 900 & - \\
\hline \multirow{8}{*}{ Nutrient Availability Index } & & - & $>0.9$ & 0.04-0.09 & $0.02-0.4$ & $<0.2$ & - \\
\hline & $\mathrm{N}$ & $\%$ & $>0.5$ & $0.5-0.08$ & $0.08-0.4$ & $<0.4$ & - \\
\hline & $\mathrm{P}$ & ppm & $>50$ & $25-50$ & $10-25$ & $<10$ & - \\
\hline & $\mathrm{K}$ & meq/100g & $>0.5$ & $0.2-0.5$ & $0.1-0.2$ & $<0.1$ & - \\
\hline & $\mathrm{pH}$ & - & $6.0-7.5$ & $5.5-6.0$ & $4.5-5.5$ & $<4.5$ & - \\
\hline & $\mathrm{Mg}$ & Cmol kg-1 & $2-5$ & $1-2$ & $<1$ & $>5$ & - \\
\hline & Organic matter & $\%$ & $>3$ & $1.5-2.9$ & $1.5-1.0$ & $<1.0$ & \\
\hline & $\mathrm{Ca}$ & Cmol kg-1 & $10-15$ & $5-10$ & $1-5$ & $<1$ & \\
\hline $\begin{array}{l}\text { Water and Nutrient Retentions } \\
\text { (R) }\end{array}$ & $\begin{array}{l}\text { Soil } \\
\text { Texture/ } \\
\text { Particle size }\end{array}$ & & $\begin{array}{l}\text { SCL, SL, } \\
\text { SC, CLL }\end{array}$ & SL AC & LS, GS & SS & $\begin{array}{l}\text { Rock } \\
\text { Land }\end{array}$ \\
\hline \multirow[t]{2}{*}{ Salt hazard (S) } & Salinity of Soil & - & Non saline & $\begin{array}{l}\text { Low } \\
\text { saline }\end{array}$ & High saline & $\begin{array}{l}\text { Vary high } \\
\text { saline }\end{array}$ & - \\
\hline & Acidity & - & $5.1-5.5$ & $5.0-4.5$ & $4.5-3.5$ & $<3.5$ & \\
\hline Topography (T) & $\begin{array}{l}\text { Landform and } \\
\text { slope }\end{array}$ & - & $\mathrm{F}$ & $\begin{array}{l}\mathrm{LT} / \mathrm{MT} / \mathrm{M} \\
\text { and slope } \\
<2.0 \%\end{array}$ & $\begin{array}{l}\mathrm{LT} / \mathrm{MT} / \mathrm{M} / \mathrm{L} \\
\text { and slope } 2- \\
5 \%\end{array}$ & $\begin{array}{l}\text { MT/M/ } \\
\text { and slope } \\
>5 \%, \text { HT }\end{array}$ & - \\
\hline \multirow[t]{3}{*}{ Nutrient retention } & $\mathrm{CEC}$ & Meg/100g & $>16$ & $10-16$ & $5-10$ & $<5$ & \\
\hline & Base saturation & $\%$ & $>60$ & $40-60$ & $20-40$ & $0-20$ & \\
\hline & Drainage & class & $0-10$ & $10-50$ & $50-150$ & 150 & \\
\hline
\end{tabular}


Determination of Land Quality Rating and Soil Physical Parameters

The nutrients mentioned earlier are the most important nutrients for rice production. After building the database, ratings were obtained for each of the nutrients as a parameter using the limitations for each by the use of spatial query.

At the end of this stage of rating, we had the following factor rating, $1=$ suitable, $2=$ moderately suitable, $3=$ marginally suitable and $4=$ not suitable for each parameter as shown below while the water body in the area was assigned the rating 6 .

\section{Final Rating of Lands Suitable gor Lowland Rice in the Study Area}

All the nutrients where overlaid and reclassed to get the thematic layer Nutrient Availability. soil texture, slope and Drainage were also overlaid and reclassed to get the layer Landform/Topography/Water retention, salinity and acidity resulted in Salt hazard map and CEC and Base saturation were overlaid and reclassed to get a map layer for Nutrient retention. The four major layers namely Nutrient Availability, Landform/Topography/Water retention, Salt hazard and Nutrient Retention were overlaid to get the suitable lands(see figures 1,3,4,above). The buffered zones/drainages and settlements were added as layers to further determine suitability (figure 4).

Determination of Aereal Extent of Soils.

Tabulate areas under the analysis module was used.. To calculate areas of urban, query for minor and major urban was done using the landuse map, the two themes were merged/dissolved and the area extent was computed using the available script. The result is presented in Table 2.

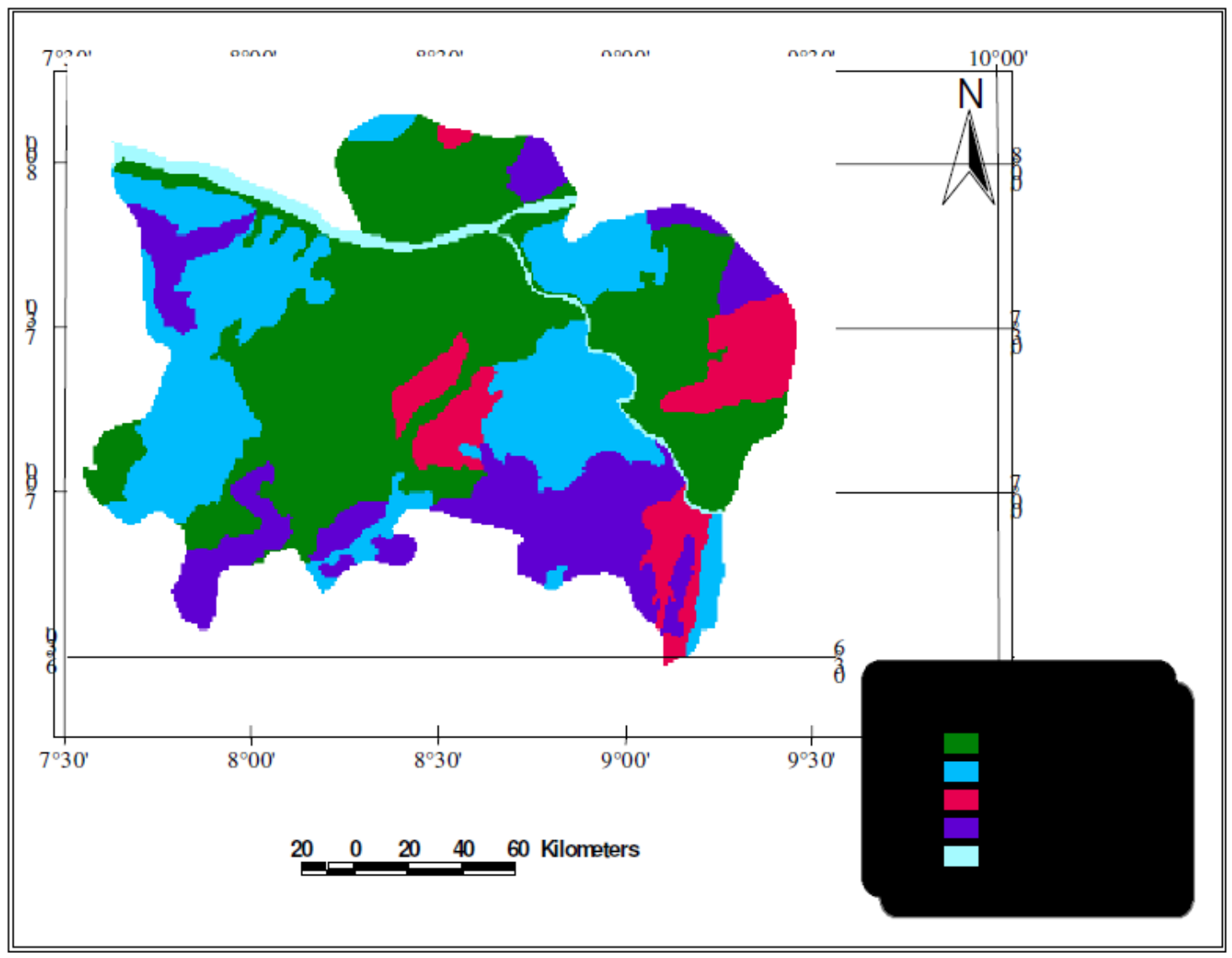

Figure 2: Map showing suitable Landform/Topography and Water Retention 
Ethiopian Journal of Environmental Studies and Management Vol. 7 Suppl. 2014

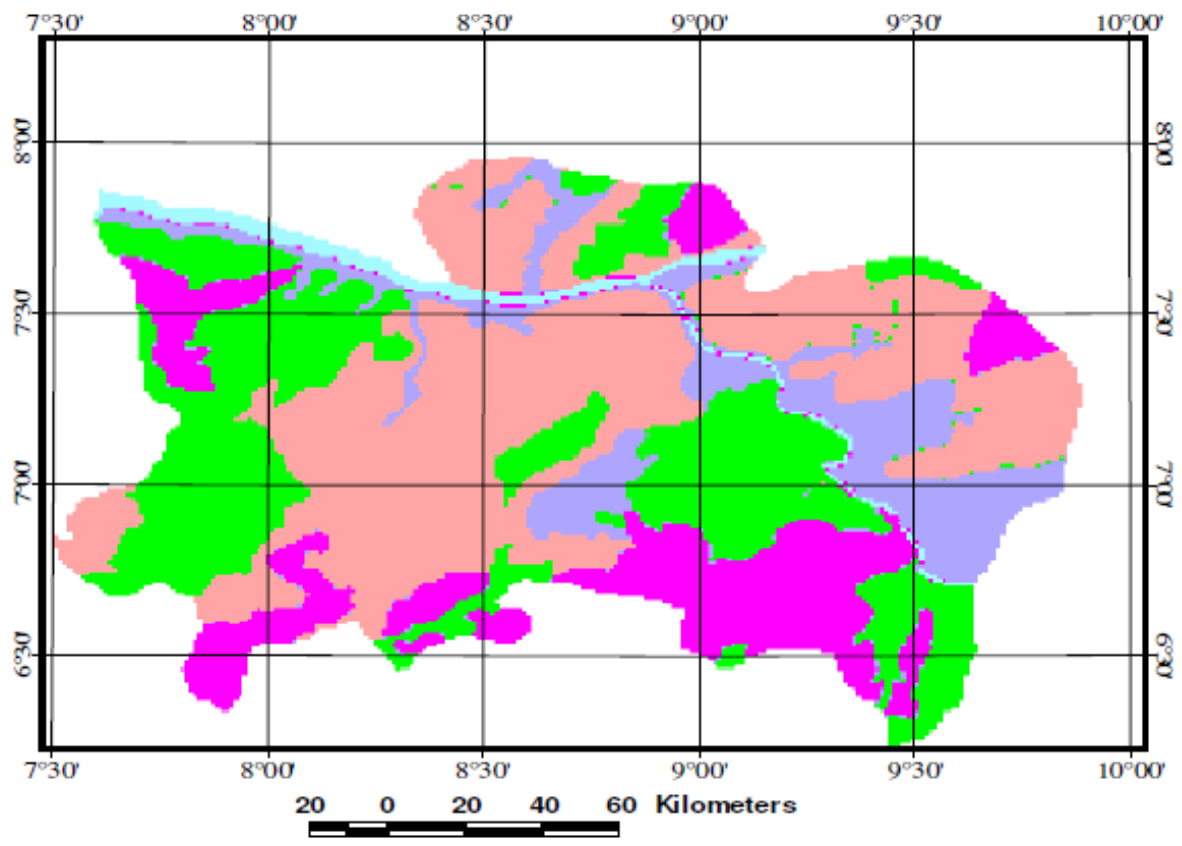

$\stackrel{N}{N}$

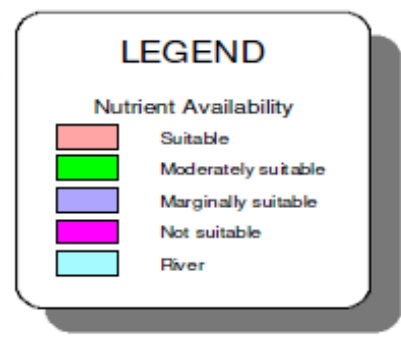

Figure 3: Map showing Nutrient Availability
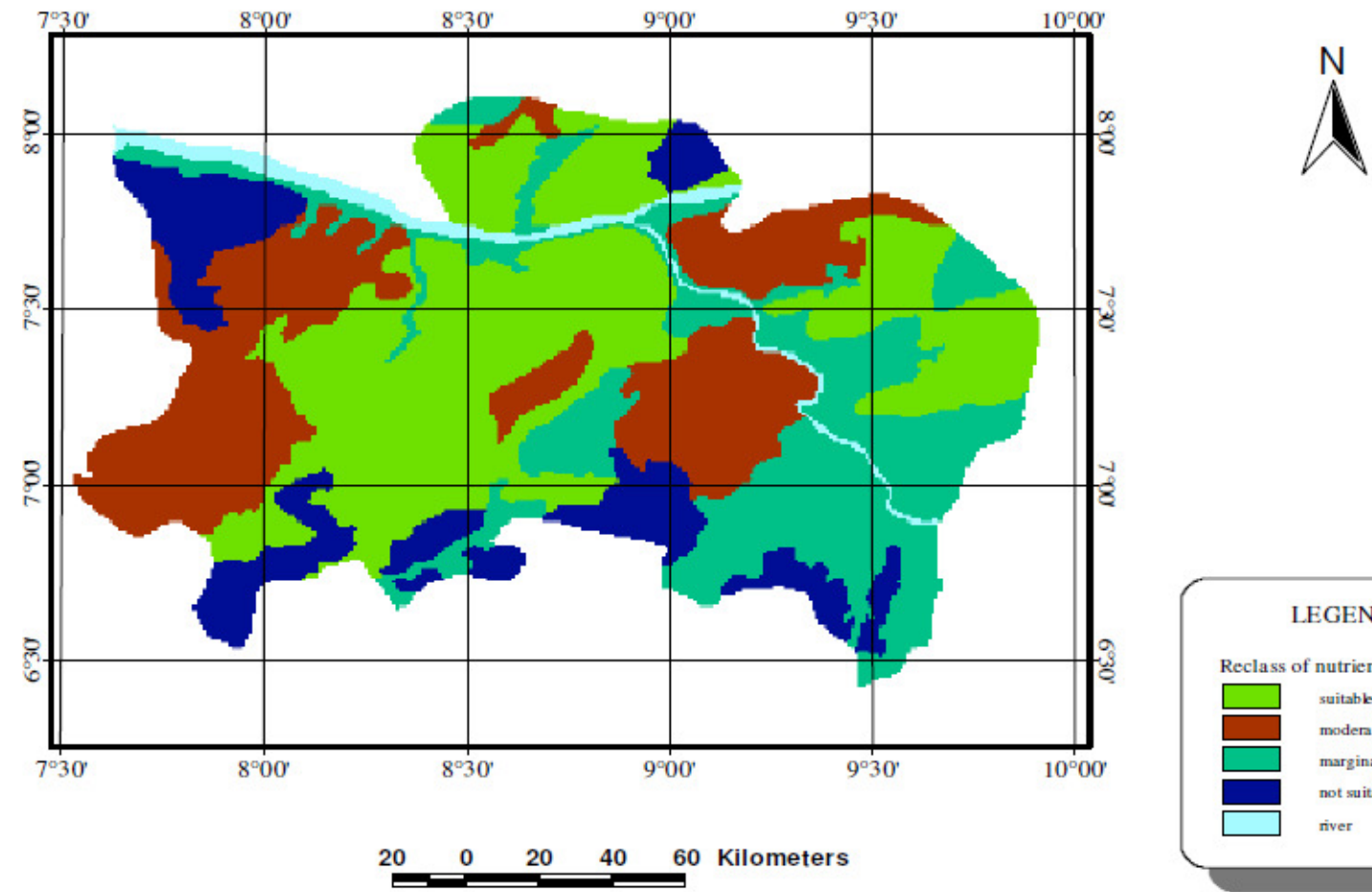

Figure 4: Map showing nutrient Retention 


\section{Results and Discussion}

The knowledge of natural resource survey and soil properties though good may not make much sense to practicing farmer. What is more useful is the degree of suitability (i.e. excellent, very good, fair or poor) of the land in terms of crop yield which groups land units into classes based on their performances or limitations when used for a sustained crop production. So here soils in the same class may had limitations of about the same degree but may varied considerably. This suitability evaluation indicated the kinds and extent of soil limitation which impede rice production. Each of the soil nutrients have different limitations that are peculiar to them in which degree may be too low thereby unsuitable and high, suitable and for some like $\mathrm{pH}$, too high unsuitable.

Benue State has perennial and constantly inundated lands (Benue valley) but the lands have been discovered like any other place to be highly variable. The reason for this work was borne amongst other issues the above variability and the urge to contribute to knowledge of the wetlands that can be utilized to increase the production of rice in Benue State and Nigeria.

The results however have shown that the lands are in serious deficit of the nutrients and other limitations the land area of the suitable lands is $1423.0612644(44.7 \%)$ with most nutrients in the 3 and 4 limitation ratings showing that they are low or limited. Nitrogen, phosphorus and potassium which are very crucial for rice production were in class 3,3 and 4 respectively and the CEC and organic matter also very low. The texture of the soil was the best, which included loamy, clay, sandy clay loam etc. with poor drainage. A combination of equations was used to extract the suitability of classes since the normal equation of picking all the classes in (1) as suitable (2) as moderately suitable, 3 as marginally suitable and 4 as unstable was not satisfied. This affected all the classes.

The moderately suitable class was also deficient both nutrients as having as low as (4) for phosphorus, mg was low being well drained and a reasonable angle of slope. Soils here were sandy loam and marginally suitable had loamy sandy, gravelly sand, which was imperfectly to well-drained and high PH values. While the last class surprisingly had some approved limitations such as low saline level, Acidity, Base saturation but majorly was unsuitable.

The suitable lands were found around the floodplains and other adjoining lands around areas like Ikpayongo, Aliade, Katsina ala, Abinsi Guma and Oturkpa areas with a land area of $14234.0612644(44.5 \%)$ The moderately suitable covered areas like Awajir, Tyowanye, Tsekpun , Obagaji and Adoka with land area of $9151.0312098 \mathrm{~km}$ (28.6\% marginally suitable covered vandeikya, parts of Adikpo Konshisha and Ushongu areas with Land area of $1372.4023436 \mathrm{~km}^{2}(4.2 \%$ and unsuitable included lands around Ogbokpo, Iqumale, Oju, parts of kwande and konshisha, Apa with land area of $6201.202400 \mathrm{~km}^{2}(19.4 \%$. The drainage had an area of $900.530116 \mathrm{~km}^{2}$ $(2.8 \%)$. The urban or built up areas were about $138.00 \mathrm{~km} 2(0.5 \%)$

The lands are well distributed across the state and of minimal distance from settlements and can be easily accessed. 

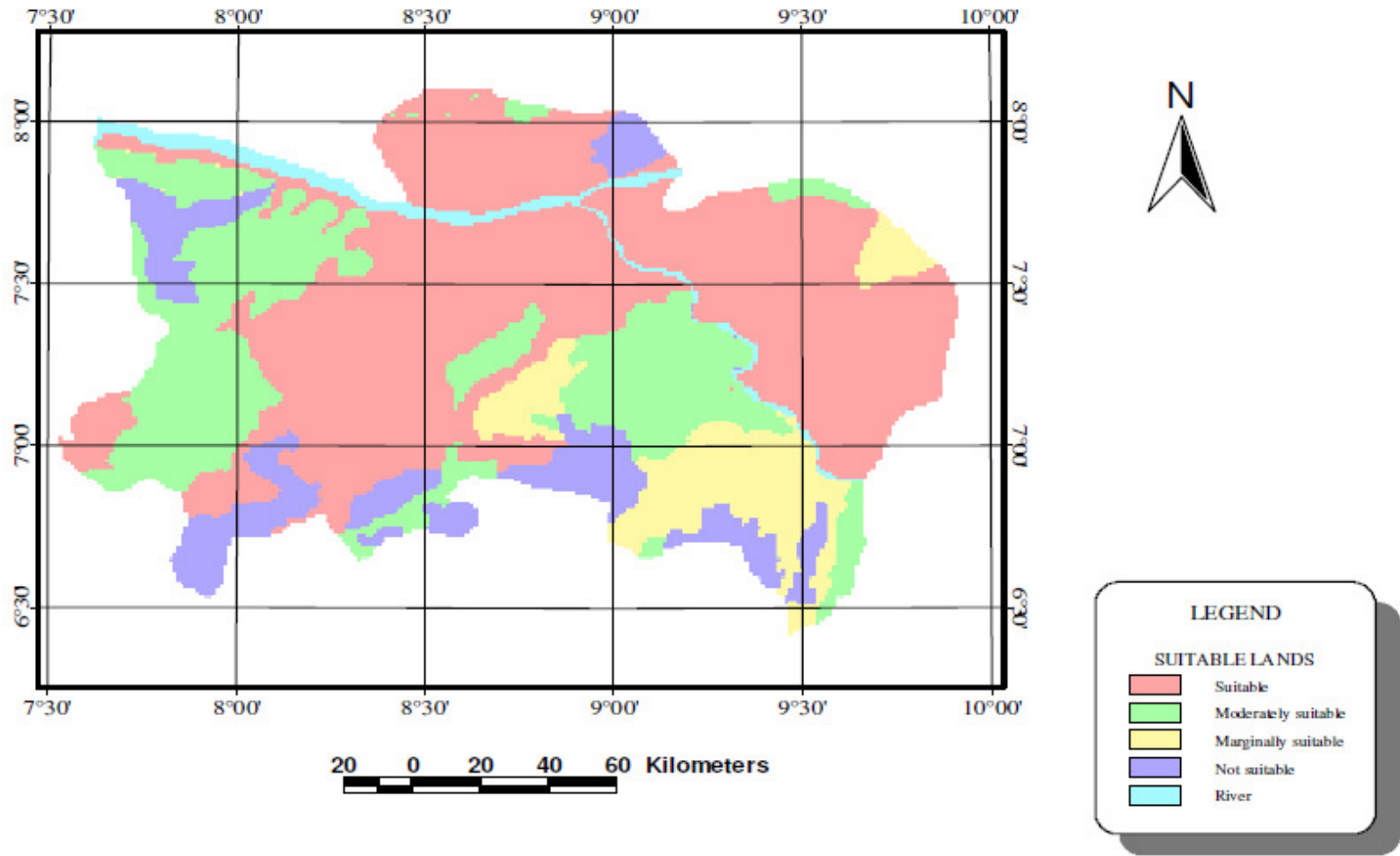

Figure 5: Map showing suitable lands

Table 2: The suitability area for rice

\begin{tabular}{lll}
\hline Suitability class & Area $(\mathrm{km}) 2$ & $\%$ \\
\hline Highly suitable & 14234.0612644 & 44.5 \\
Moderately suitable & 9151.0312098 & 28.6 \\
Marginally suitable & 1372.4023436 & 4.2 \\
Unsuitable & 6201.2020400 & 19.4 \\
(water body) & 900.530116 & 2.8 \\
Urban & 138.00 & 0.5 \\
Total & 31997.2269738 & 100 \\
\hline
\end{tabular}



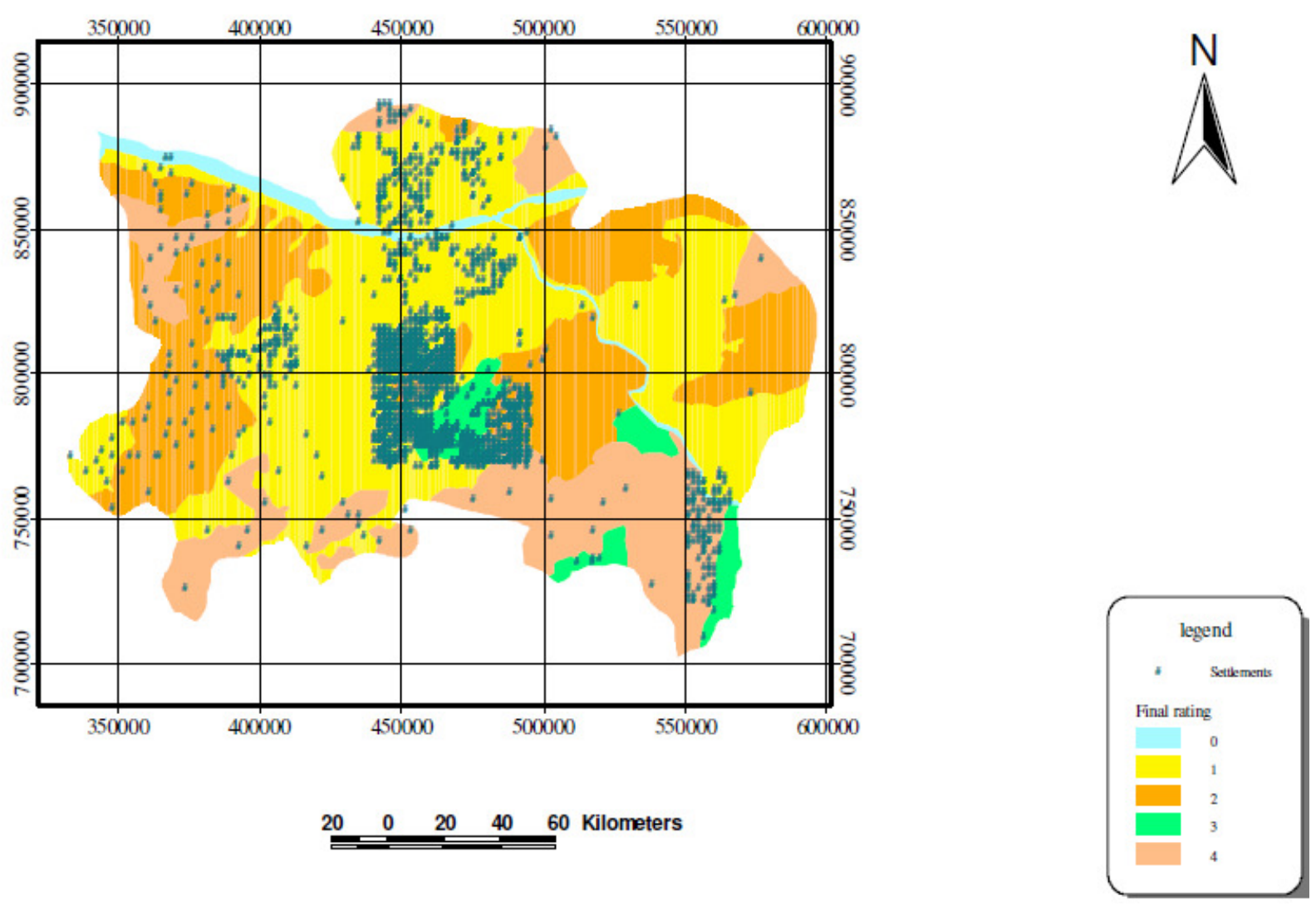

Figure 6: Final suitability rating with settlements.

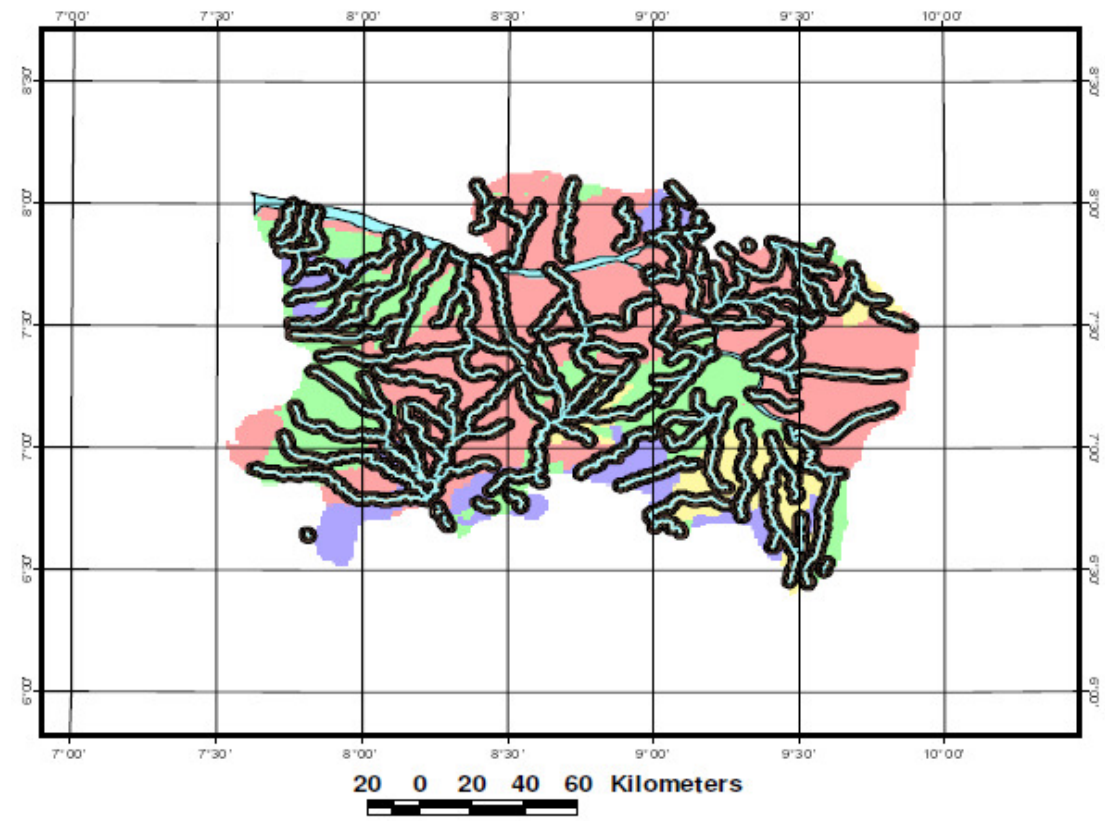

$\stackrel{N}{\wedge}$

Figure 7: Maps showing buffered zones

minor Drainage shp

Buffer 2 of minor Drainage.shp

Suitable

Moderately suitable

Marginally suitable

Major Drainage

SUITABLE LANDS

Suitable

Moderately suitable

Marginally suitable

Not suitable

River 


\section{Conclusion and Recommendation}

According to literature (IRRI 1969; Robert, 1992) low levels of nutrients and exchangeable cations is usually due to leaching, weathering and ferrolysis hence low fertility coupled with intermittent flooding and drying. High organic matter again is explained with poor drainage. As a result of the above I will recommend the use of fertilizer- (Nitrogen phosphorus, potassium fertilizers), more effort should be made towards a more systemized micro nutrient investigation in the state and management of the above should be of utter most importance. Also, the use of rice varieties that can survive these conditions such as Nicera should be employed.

Different Types of cultivation system and soil conservation systems should be discovered. More studies should be made and used of technologically, mechanization, maintaining good funding and provision of facilities such as roads, markets and so on should be adopted. GIS should however be adopted to achieve all these efficiently with other specialists, such as agriculturalist, soil pedologist, and so on. Land within mapping unit 24 and 22 should be used as forest reserve and wildlife park while other degraded lands within the state should be reclaimed for suitable uses.

The techniques of Geographic information Systems were employed in selecting suitable locations for lowland rice cultivation in Benue State. Specifically, basic climatic and soil requirements for rice production were collected, ranked and assigned weights in accordance with their perceived relative importance to rice production. this information was then processed using GIS techniques in order to identify areas within Benue State suitable for rice production.

\section{References}

FAO (1979). Land in Sierra Leone. A Reconnaissance Survey and Evaluation for Agriculture Technology: Report 1 Rome.

Final Report (2001). Feasibility studies on the impact of imminent Explosion of lake Nyos on mount Cameroon on River Katsina-Ala and Benue Floodplains by Sigwa Nigeria Limited for Benue state Government. Geneva Switzerland

Forestry Monitoring Evaluation and Coordinating Ministry (1998). State Environmental Action Plan of Benue State

McNamara, K.S. (2003). Information and communication Technologies, poverty and development: learning from Experience

Opku-Apan, A. (2000). Rice production Practices in Mankrau valley, Ashanti Region Ghana. Crop Research institute Kumasi Ghana.

Presidential initiative (2003). Federal Department of Agriculture (progress in implementation of presidential initiative on Rice, Cassava, and vegetable oil Development Programme.

Proceedings of the National fertilizer seminar October 28-30 (1987). Towards Efficiency of Fertilizer use and development in Nigeria (Port Harcourt) Federal ministry of Agriculture, water resource and rural development.

Robert, F.C. (1992). History of the International Rice Research Institute, Manila Philippines.

Semi detailed soil survey of Benue flood plain phase two (1985). Draft final; Main Report by Abbstal Nigeria limited for Federal ministry of water Resources Lagos. 
Application of Geographic Information Systems in Land Suitability Rating................ADE, M.A.

Soil Report (1985). "The Reconnaissance Soil survey of Benue state Nigeria Federal Department of Agricultural Land Resources".

Sys (1985). Crop specitic assessment,Food Agriculture Organisation of United Nations, Rome

www. Gisdevelopment net: A physical Evaluation of Land suitability for Rice: A methods logical study using Gis (1997) www. Gisdevelopment net: Assessment of ERS-1 SAR Data for rice crop mapping and monitoring (1999).

www. Warda Cgiar. Org/warda (2001) NERICAs Rice for Life WARDA.

Yukiyo, Y. (2003). Land suitability analysis concerning water resources and Soil property JIRCAS working report (in Press). 